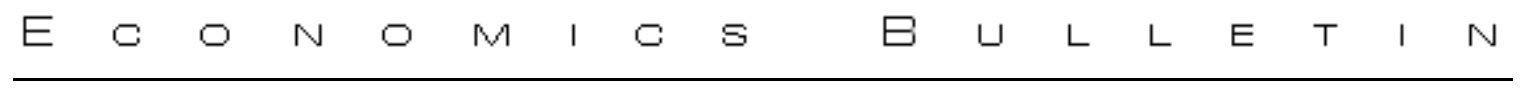

\title{
One Proposition about Dynamic Portfolio Selection in an Open Economy and International Diversification
}

\author{
Takaaki Aoki \\ State University of New York at Buffalo, Department of Economics
}

\begin{abstract}
This paper describes one proposition about dynamic Markowitz portfolio selection in a two-country open economy. Here it is proved that, assuming that two countries in an open economy share the same risk absolute aversion coefficient and the same information set with some conditions, the portfolio each country holds always attains the same rate of return, regardless of any other symmetric/asymmetric characteristics of the open economy. One basic implication of this proposition is that, when two countries share the common information set, each country might be, under these non-general conditions, indifferent, regarding the allocation of home/foreign risky assets, to the diffusion of exchange rate price process. Finally, I discuss another implication of this proposition in the relation with international portfolio diversification and so calledgthe home bias puzzleh.
\end{abstract}

\footnotetext{
I am grateful to anonymous referees. The working paper version, which contains a rigorous proof of stated proposition, can be requested to the author upon e-mail request.

Citation: Aoki, Takaaki, (2008) "One Proposition about Dynamic Portfolio Selection in an Open Economy and International Diversification." Economics Bulletin, Vol. 6, No. 18 pp. 1-8

Submitted: January 17, 2008. Accepted: April 21, 2008.

URL: http://economicsbulletin.vanderbilt.edu/2008/volume6/EB-08F30006A.pdf
} 


\section{Model and Proposition}

In this section, we set a simple model of dynamic Markowitz portfolio selection in a two-country open economy, and at last claim one proposition.

\section{Organization of an open economy}

We assume an open economy with two countries, two distinct risk-free assets, and two distinct, risky assets, one of which represents respectively one of two countries. Each risk-free asset is regarded as each country 's own currency, and is also exchangeable with each other. (So, needless to say, each country may hold the other country's assets.) Assume the discrete time flow, $t=0,1,2, \ldots$. Also, we denote each country, a representative economic agent, by $k=1,2$. In addition, the proportion of each country in its personal asset holdings as of time $\mathrm{t}\left(\mathrm{A}_{\mathrm{k}, \mathrm{t}}\right)$, being $p$ for country 1 and $1-p$ for country $2 .^{1}$

\section{Price processes}

In country 1 there exist one risk-free asset, denoted by fa, and one risky asset, rb, while in country 2 one risk-free asset, fc, and one risky asset, $r d$, do. Defining the allocation of each asset (fa, rb, fc, rd) for country $\mathrm{k}(\mathrm{k}=1,2)$ respectively as $z_{k, a, t}, z_{k, b, t}, z_{k, c, t}$ and $z_{k, d, t}$, then the price process of each asset (fa, rb, fc, rd) as of time $\mathrm{t}$ are assumed to be represented as following: ${ }^{2}{ }^{3}$

$$
\begin{aligned}
& \Delta \ln S_{a, t}=r_{a} \Delta t \\
& \Delta \ln S_{b, t}=v_{b} \Delta t+g_{b, t-1}{ }^{T} \gamma_{b}+\sigma_{b} \Delta B_{b, t}+\eta_{b} \cdot\left\{p \cdot \Delta z_{1, b, t}+(1-p) \cdot \Delta z_{2, b, t}\right\} \\
& \Delta \ln S_{c, t}=r_{c} \Delta t \\
& \Delta \ln S_{d, t}=v_{d} \Delta t+g_{d, t-1}{ }^{T} \gamma_{d}+\sigma_{d} \Delta B_{d, t}+\eta_{d} \cdot\left\{p \cdot \Delta z_{1, d, t}+(1-p) \cdot \Delta z_{2, d, t}\right\}
\end{aligned}
$$

Here, $\eta_{b}$ and $\eta_{d}$ are the demand elasticities of the market prices, $g_{b, t-1}{ }^{T}$ and $g_{d, t-1}{ }^{T}$ are the row vectors containing complete information sets regarding the price processes, $\Delta B_{b, t}$ and $\Delta B_{d, t}$ are the standard Brownian motions, $v_{b}$ and $v_{d}$ are the drifts, $\sigma_{b}$ and $\sigma_{d}$ are the diffusions, for risky asset $\mathrm{rb}$ and $\mathrm{rd}$, respectively. Let $\left\{\Delta \ln S_{e x, t}\right\}_{t \rightarrow \infty}$ denote the exchange rate price process of the risk-free asset in country 1 (fa) to the risk-free asset in country 2 (fc). Then, with no arbitrage condition,

$$
\Delta \ln S_{e x, t}=v_{e x} \Delta t+\sigma_{e x} \Delta B_{e x, t}+\eta_{e x}\left\{-p \cdot\left[\Delta z_{1, c, t}+\Delta z_{1, d, t}\right]+(1-p) \cdot\left[\Delta z_{2, a, t}+\Delta z_{2, b, t}\right]\right\} \quad(1.2)^{4}
$$

\footnotetext{
1 As seen later, the self-financing and utility maximizing portfolio selection strategy keeps the asset proportion of each country $(p)$ automatically constant under some assumptions of the proposition.

$2 z_{k, a, t}+z_{k, b, t}+z_{k, c, t}+z_{k, d, t}=1$ (for $\mathrm{k}=1,2$ and for all $\mathrm{t}$.).

${ }^{3}$ The notation, $\Delta$, represents the difference of time $t+1$ from time $t$.

${ }^{4}$ The no-arbitrage condition in the exchange rate process between two contries imposes an additional restriction, $v_{e x}=-\left(r_{c}-r_{a}\right)$.
} 


\section{Estimation and forecast}

Assume that the price process of a risky asset (denoted by r=rb, rd, say), $\left\{\Delta \ln S_{r, t}\right\}_{t \rightarrow \infty}$ is already revealed until time $\mathrm{t}-1$. Then define its past history and the explanatory variable (information set) matrix as following.

$$
\begin{aligned}
y_{t-1} \equiv\left[\begin{array}{c}
\Delta \ln S_{r, t-1} \\
\Delta \ln S_{r, t-2} \\
\mathrm{M} \\
\Delta \ln S_{r, t-T_{e}}
\end{array}\right] \quad\left(\mathrm{T}_{\mathrm{e}}{ }^{*} 1 \text { column vector of the dependent variable. }\right) \\
X_{t-1} \equiv\left[\begin{array}{c}
x_{t-1}{ }^{T} \\
x_{t-2}^{T} \\
\mathrm{M} \\
x_{t-T_{e}}^{T}
\end{array}\right] \equiv\left[\begin{array}{c}
x_{1, t-1}, \Lambda, x_{J, t-1} \\
x_{1, t-2}, \Lambda, x_{J, t-2} \\
\mathrm{M} \\
x_{1, t-T_{e}}, \Lambda, x_{J, t-T_{e}}
\end{array}\right] \quad\left(\mathrm{T}_{\mathrm{e}}{ }^{*} \mathrm{~J} \text { explanatory variable matrix. }\right)
\end{aligned}
$$

Here, $\mathrm{T}_{\mathrm{e}}\left(\mathrm{t}-1, \mathrm{t}-2, \ldots, \mathrm{t}-\mathrm{T}_{\mathrm{e}}\right)$ denotes the past periods on which the estimate is based, and $X_{t-1}$ is a common explanatory variable matrix for each country, $\mathrm{k}=1,2$. The first column vector of $X_{t-1}$ is a summer vector, all elements of which are 1's. For one example, the first row vector of $X_{t-1}$, $x_{t-1}^{T} \equiv\left[x_{1, t-1}, \Lambda, x_{J, t-1}\right]$, contains 1, $g_{b, t-1}^{T}, g_{d, t-1}^{T}, p \cdot \Delta z_{1, b, t}, p \cdot \Delta z_{1, c, t}, p \cdot \Delta z_{1, d, t}$, $(1-p) \cdot \Delta z_{2, a, t},(1-p) \cdot \Delta z_{2, b, t}$ and $(1-p) \cdot \Delta z_{2, d, t}$. We also define the above matrix and apply them to the following Neoclassical Regression Model.

$$
y_{t-1} \sim N\left(X_{t-1} \beta_{r}, \sigma_{t}^{2} I\right)
$$

where $X_{t}$ is non-stochastic and $\operatorname{rank}\left(X_{t-1}\right)=J$, and $I$ is an identity matrix.

We assume that each country, $\mathrm{k}=1,2$, believes that this model applies. However, it does not have to be true. Then, defining $Q_{t-1} \equiv X_{t-1}{ }^{T} X_{t-1}, \quad A_{t-1} \equiv Q_{t-1}{ }^{-1} X_{t-1}{ }^{T} \quad, \quad N_{t-1} \equiv X_{t-1} A_{t-1}$, $M_{t-1} \equiv I-N_{t-1}$ and $e_{t-1} \equiv M_{t-1} y_{t-1}$, the estimated value of the variance of return $\left(\hat{\sigma}_{t}^{2}\right)$ can be represented as follows.

$$
\hat{\sigma}_{t}^{2}=\frac{e_{t-1}^{T} e_{t-1}}{T_{e}-J}
$$

The forecast value of the expected rate of return as of time $\mathrm{t}\left(\hat{v}_{t}\right)$ can be represented as follows.

$$
\hat{v}_{t}=x_{t}^{T} Q_{t-1}^{-1} X_{t-1}{ }^{T} y_{t-1}
$$

$$
\text { where } x_{t}^{T} \equiv\left[x_{1, t}, \Lambda, x_{J, t}\right] \text { is the first row vector of the explanatory variable matrix, }
$$

$X_{t}$

\section{Expected utility}

Each country's expected utility function at time $t-1$ is a function of the rate of return $\left(\Delta \ln A_{k, t}\right)$, and takes the following form. ${ }^{5}$

5

$$
\begin{aligned}
& \Delta \ln A_{1, t}=z_{1, a, t+1} \Delta \ln S_{a, t}+z_{1, b, t+1} \Delta \ln S_{b, t}+z_{1, c, t+1}\left(\Delta \ln S_{c, t}+\Delta \ln S_{e x, t}\right)+z_{1, d, t+1}\left(\Delta \ln S_{d, t}+\Delta \ln S_{e x, t}\right) \\
& \Delta \ln A_{2, t}=z_{2, a, t+1}\left(\Delta \ln S_{a, t}-\Delta \ln S_{e x, t}\right)+z_{2, b, t+1}\left(\Delta \ln S_{b, t}-\Delta \ln S_{e x, t}\right)+z_{2, c, t+1} \Delta \ln S_{c, t}+z_{2, d, t+1} \Delta \ln S_{d, t}
\end{aligned}
$$




$$
E_{t-1} u_{k}^{t}=E_{t-1}\left[-\exp \left(-\alpha_{k}\left(1+\Delta \ln A_{k, t}\right)\right)\right]
$$

where $A_{k, t}$ is the total asset value of the country $\mathrm{k}(=1,2)$ at time $\mathrm{t}$.

This utility function possesses a constant coefficient of absolute risk aversion $\left(\alpha_{k}\right)$, and is upwardly concave over $A_{k, t}$ 's entire domain (including where $A_{k, t}$ is negative). Each country holds a portfolio consisting of a risk-free asset and risky assets. The future expected rate of return and variance for each risky asset are estimated based on the past history of explanatory variables, and the portfolio allocation, overall expected rate of return, and overall variance and determined so as to maximize expected utility for the following period. For example, consider the case in which a country has to determine the allocation $\left(z_{t}\right)$ of risky assets ( $\mathrm{r}$, say) for the next time $\mathrm{t}$ (and hence the allocation $\left(1-z_{t}\right)$ of the risk-free asset (f, say)) as follows.

$$
z_{t}=\arg \max E_{t-1}\left(-\exp \left(-\alpha\left(1+\Delta \ln A_{t}\right)\right)\right)
$$

Since the (excess) rate of return follows a normal distribution, and we denote the allocation of the risky asset by $z_{t}$ and therefore that of a risk-free asset by $1-z_{t}$, then the allocation $z_{t}$, which maximizes the expected utility for the next time ( $t$ ), is calculated, as a well-known result, in the following formula.

$$
z_{t}=\frac{\hat{v}_{t}-r_{f}}{\alpha \cdot \hat{\sigma}_{t}^{2}}
$$

where $\alpha$ is an absolute risk aversion coefficient.

Now we claim the following proposition.

Proposition. Assume that the absolute risk aversion coefficients are the same in both countries $\left(\alpha_{1}=\alpha_{2}\right)$. Then, the allocation of risky assets ( $r b$ in country 1 and $r d$ in country 2$)$ are always the same for both countries for all $t$. That is:

$$
z_{1, b, t}=z_{2, b, t}, \quad z_{1, d, t}=z_{2, d, t}
$$

Furthermore, $z_{1, a, t}=1+z_{2, a, t}, \quad z_{1, c, t}=z_{2, c, t}-1 \quad$ for all $\mathrm{t}$

In addition, the rates of return in the personal asset holdings are always the same for both countries for all $\mathrm{t}$.

$$
\Delta \ln A_{1, t}=\Delta \ln A_{2, t} \quad \text { for all } \mathrm{t}
$$

Note that these relationships should hold regardless of the values of $r_{a}, r_{c}, v_{b}, v_{d}$, $v_{e x}, \sigma_{b}, \sigma_{d}, \sigma_{e x}, \eta_{b}, \eta_{d}, \eta_{e x}, \gamma_{b}, \gamma_{d}$ or $p$.

The proof is shown in the working paper version of this article. ${ }^{6}$

6 The proof of this proposition uses some results as in Constantinides et al. (1995). 


\section{Final remarks- International Diversification and Home Bias Puzzle}

The proposition presented in this paper has an interesting economic implication in the sense that it always holds, (1) regardless of the characteristics of each country's risky asset market, including the demand elasticity of market prices, and (2) regardless of the value of the proportion in each country's personal asset holdings ( $\mathrm{p}$ for country 1 and 1-p for country 2), and (3) regardless of the characteristics of the exchange rate price process (so, whether each country's riskless asset, represented mainly by its currency, is devaluating or revaluating against the other country's), and (4) regardless of the risk free rate in each country (that is, $r_{a}=r_{c} \equiv r$ is not required.), which is supposed to be fixed as a result of each country's monetary policy. Instead, we just need that each country shares the same risk aversion coefficient $\left(\alpha_{1}=\alpha_{2} \equiv \alpha\right)$, and the same explanatory variables (the same information set), $X_{t-1} \cdot{ }^{7}$

This proposition is not a result which can be necessarily derived from conventional general/partial equilibrium theories, but that obtained from a formal coincidence in mathematical formulation combined between the risk-minimizing (risky) portfolio selection and the utility maximizing allocation of risky/riskfree assets under the CARA utility and normality assumptions, as shown in equation (1.9). For example, (1.9) easily breaks, if we abandon the CARA utility or the normality assumption, therefore, in these cases, the proposition does not hold. Instead, it always holds regardless of the market formation in each country (for example, perfectly/imperfectly competitive, or etc). Also, it always holds even if the underlying economic system is not in equilibrium, because we do not assume any market clearing condition here, and in addition, because no-arbitrage condition in the exchange rate process between two countries, $v_{e x}=-\left(r_{c}-r_{a}\right)$ as in (1.2), is not needed at all, and all of these aspects show that this proposition is not a derivative result from general/partial equilibrium theories, but one peculiar mathematical aspect derived from a peculiar matching in formulation within an open economy framework. For example, the allocation for riskfree assets in each country may not be, in general, the same for any period. $\left(z_{1, a, t} \neq z_{2, a, t}\right.$

and $z_{1, c, t} \neq z_{2, c, t}$, while $\left.z_{1, a, t}+z_{1, c, t}=z_{2, a, t}+z_{2, c, t}.\right)$

Now consider the simplest case where two countries are in symmetry. For example, assume $r_{a}=r_{c}$, $v_{b}=v_{d}, \quad \sigma_{b}=\sigma_{d}, \eta_{b}=\eta_{d}, v_{e x}=0, p=0.5$. Also, $\Delta B_{b, t}, \Delta B_{d, t}$ and $\Delta B_{e x, t}$ do not have to be independent with each other, but the correlations need to be symmetric between two countries. $^{8}$ Then, from symmetry in the economic system together with (1.10) and (1.11), each

7 Of course, the assumptions of this proposition, which implicitly take account of cross sectional dependences among panel units, is only a possibility among many.

8 Also, assume that the information sets, $g_{b, t-1}{ }^{T}$ and $g_{d, t-1}^{T}$ are generated from symmetric nature 
country is supposed to hold the same portion of two risky assets ( $\mathrm{rb}$ and $\mathrm{rd}$ ) in an ergodic sense, that is: ${ }^{9} \quad 10$

$$
\bar{z}_{1, b}=\bar{z}_{1, d}=\bar{z}_{2, b}=\bar{z}_{2, d} \equiv \bar{z}_{r}
$$

where the upper bar denotes the mean over $t$.

Also, from (2.1) and (1.10/11), we have for country 1:

$$
\begin{aligned}
& \bar{z}_{1, d}=-\bar{z}_{1, c}\left(=\bar{z}_{1, b}=\bar{z}_{r}\right), \quad \bar{z}_{1, a}=1-\bar{z}_{1, b}\left(=1-\bar{z}_{r}\right) \equiv \bar{z}_{f} \\
& \text { where } \bar{z}_{r}+\bar{z}_{f}=1
\end{aligned}
$$

This is somewhat counter intuitive, because, for example for country 1, clearly country 2's risky asset (rd) is more "risky" than its own risky asset (rb) because of the exchange rate volatility. But we easily see, in the first equation of (2.2), that all the part of volatility in foreign risky asset rd, attributed to exchange rate process, is completely hedged by holding the same amount of liability in foreign riskfree asset fc. ${ }^{11} 12$ Therefore, each symmetric country is, in the long run (in an ergodic sense), perfectly neutral against the exchange rate volatility $\left(\sigma_{e x}\right)$. The allocation of home/foreign risky assets ( $\mathrm{rb}$ and $\mathrm{rd}$ ) itself is not only equated between them, as shown in (2.1), but also each country does really respond to the increase in the volatility of exchange rate process rather by keeping the total portion of home/foreign riskfree assets $\left(\bar{z}_{1, a}+\bar{z}_{1, c}\left(=\bar{z}_{2, a}+\bar{z}_{2, c}\right)\right)$ constant. Also, the long-run mean proportion of risky asset in domestic financial markets $\left(\bar{z}_{1, b} /\left(\bar{z}_{1, a}+\bar{z}_{1, b}\right)=\bar{z}_{1, b}\right)$ does not change either with the larger volatility of exchange rate $\left(\sigma_{e x}\right)$. One basic implication of this proposition under this symmetry assumption is that, when two countries share the common information set, each country might be, under some non-general conditions, indifferent, between its homelforeign risky asset holdings ( $r b$ and $r d$ ), to the diffusion (volatility) of exchange rate price process, which is completely hedged by balancing the debt/holding of foreign riskfree/risky assets (fc and $r d$ ), so that each country always equates the allocation for each risky asset ( $r b$ and $r d$ ). This aspect strongly supports each country's considerable gain from international portfolio diversification, as emphasized in Grauer and Hakansson (1987). On the other hand, under asymmetry assumption,

(the same functional form of stochastic distribution or etc.).

9 In general, $z_{1, b, t} \neq z_{1, d, t}, \quad z_{2, b, t} \neq z_{2, d, t}$.

10 The symmetry assumption requires, $\bar{z}_{1, b}=\bar{z}_{2, d}, \bar{z}_{1, c}=\bar{z}_{2, a}$ and $\bar{z}_{1, d}=\bar{z}_{2, b}$.

11 This is also counter intuitive and is not rigorously true for each respective period $t$, because the information set $X_{t-1}$ is just stochastically generated. It holds only in an ergodic sense.

12 As a matter of fact, the country can attain the same return (but the larger volatility, therefore the smaller utility gain) in a closed economy framework, dealing with only domestic assets fa and rb where:

$$
\bar{z}_{1, a}{ }^{\prime}=2 \bar{z}_{f}-1, \quad \bar{z}_{1, b}{ }^{\prime}=2 \bar{z}_{r}
$$


for example where $v_{e x} \neq-\left(r_{c}-r_{a}\right)$, in general (2.1) and (2.2) do not hold, so that $\bar{z}_{1, d} \neq-\bar{z}_{1, c} \cdot{ }^{13}$

This inequality implies that the exchange rate volatility is not completely, but only partially canceled off, therefore the larger $\sigma_{e x}$ surely causes the increase in home riskfree asset fa, while the sign of change in home risky asset rb is still uncertain. Even in this (asymmetry) case, each country is still indifferent to the exchange rate volatility in the sense that both countries hold the same share in risky asset $\mathrm{rb}$ and rd respectively, as shown in (1.10/11). In other words, the existence of exchange rate volatility does not actually make each country discriminate regarding the relative allocation in home/foreign risky assets ( $\mathrm{rb}$ and $\mathrm{rd}$ ).

Finally, within the framework of this model, I state some points, apart from some important explanations including "non-traded goods or small utility gains to diversification", in the relation with so called "the home bias puzzle", which is known as "the contradiction between the obvious benefits of holding a globally dispersed set of equities and the apparent reluctance to do so" (Obstfelt and Rogoff. (1996), Tesar and Werner (1995)). Some analyses regarding international portfolio diversification appear, for example, in Grauer and Hakansson (1987), Hui (2005), Byers and Peel (1993), Allen and Macdonald (1995) Espitia and SantamarÍa (1994), or Babilis and Fitzgerald (2005). Also, Coakely, Fuertes and Smith (2006) and Drine and Rault (2007) offer nice examples in both econometric (panel data) and computational analysis of international finance including PPP puzzle.

\section{Missing information and mis-specified model}

As easily imagined, in case that, for example, one country does not hold some information attributed to the other country (for example, $g_{d, t-1}{ }^{T}, \Delta z_{2, c, t}$ and $\Delta z_{2, d, t}$ for country 1), the regression model is made under mis-specification, which necessarily causes a larger estimated variance and smaller allocation of foreign assets (fc and rd for country 1). ${ }^{14}$ This, the most plausibly, explains the home bias puzzle, but I exclude it from my focus, since it is not a novel illustration. Also, it is noteworthy that even under misspecification, if two countries share the same information set $X_{t-1}$, then still the proposition holds and the home bias should disappear.

\section{Borrowing constraints}

Again, consider country 1 asset holdings in the symmetric case. Then in (2.2), the allocation of

$13 v_{e x} \neq-\left(r_{c}-r_{a}\right)$ implies that the exchange rate process is in disequilibrium and does not meet no-arbitrage condition.

14 Also, the missing information about demand/supply gap of each assets $\left(\Delta z_{1, b, t}, \Delta z_{1, c, t}, \Delta z_{1, d, t}\right.$, $\Delta z_{2, a, t}, \Delta z_{2, b, t}$ and $\left.\Delta z_{2, d, t}\right)$ induces the estimated residual of each price process to be correlated over time $t$. 
foreign riskfree asset ( $\mathrm{fc}$ ) is just negative of that of foreign risky asset (rd), and the total portion for foreign assets is just zero $\left(\bar{z}_{1, d}+\bar{z}_{1, c}=0\right)$. The key point is that, in order to be risk neutral against exchange rate volatility and fully to enjoy the utility gain from international portfolio diversification, the investors must borrow the same amount of foreign riskfree asset as the foreign risky asset holding. If this violates the borrowing constraint, which the authority might impose for foreign investors, then necessarily we have $\bar{z}_{1, d}<\bar{z}_{1, b}$, which is also one persuasive illustration of the home bias puzzle. $^{15}$

\section{CRRA (constant relative risk aversion) utility}

\section{Non-normality of disturbance terms}

Another possibility is that the above two points might also explain the home bias puzzle, that is, too excessive, empirically observed emphasis on the risky asset in home country. Under a constant relative risk aversion or an upwardly deviated asymmetric distribution of disturbance terms, a smaller risk premium and a larger incentive for holding home country risky asset might be induced for each country than under CARA or a symmetric normal distribution. In other words, in these circumstances the common information sharing might not ensure that the diffusion of exchange rate can be perfectly hedged by adjusting the total amount of home/foreign riskfree assets. Therefore, it might be worth doing simulation, which cannot be replaced with analytical work, under a careful specification of the parameter values and the form of distributions, to examine this hypothesis within the framework of the model.

\section{References}

Constantinides, G.M. and A.G. Malliaris (1995) "Portfolio Theory (Chapter 1)", Handbooks in OR \& MS, Vol.9 (R. Jarrow et al. Eds.), Elsvier Science

Grauer, Robert R and Nils H. Hakansson (1987) "Gains from International Diversification: 1968-1985 Returns on Portfolio of Stocks and Bonds”, Journal of Finance, Vol.42, pp.721-739, July 1987

Obstfeld, Maurice and Kenneth Rogoff (1996) "Foundation of International Macroeconomics", The MIT Press, pp.304-306, pp.325-332

Tesar, Linda L. and Ingrid Werner (1995) "Home Bias and High Turnover", Journal of International Money and Finance, Vol.14, pp.467-492, August 1995

Hui, Tak-Kee (2005) "Portfolio diversification: a factor analysis approach", Applied Financial Economics, Vol. 15, Issue 12, pp. 821-834, Aug. 2005.

Byers, J.D. and D. A. Peel (1993) "Some evidence on the interdependence of national stock markets and the gains from international portfolio diversification", Applied Financial Economics, Vol. 3, Issue 3, pp. 239-242, Sep. 1993.

Allen, D. E. and G. Macdonald (1995) "The long-run gains from international equity diversification: Australian evidence from cointegration tests", Applied Financial Economics, Vol. 5, Issue 1, pp.

15 For foreign investors, as is country 1 investor in country 2, the borrowing constraint might be naturally $z_{1, d, t} \geq 0, z_{1, c, t} \geq 0$, while for domestic investors, as is country 2 investor in country 2 , it might be, more loosely, $z_{2, d, t}+z_{2, c, t} \geq 0$. The condition $\bar{z}_{1, d}+\bar{z}_{1, c}=0$ does not actually wipe out the high possibility of default in next period, that is $z_{1, d, t+1}+z_{1, c, t+1}<0$. 
33-42, Feb. 1995.

Espitia M. and R. SantamarÍla (1994) "International diversification amomg the capital markets of the EEC", Applied Financial Economics, Vol. 4, Issue 1, pp. 1-10, Feb. 1994.

Babilis, Sophia and Valpy Fitzgerald (2005) "Risk Appetite, Home Bias and the Unstable Demand for Emerging Market Assets", International Review of Applied Economics, Vol. 19, Issue 4, pp. 459-476, Oct. 2005.

Coakely, Jerry, Ana-Maria Fuertes and Ron Smith (2006) "Unobserved Heterogeneity in Panel Time Series Models", Computational Statistics \& Data Analysis, Vol. 50, Issue 9, pp. 2361-2380, May 2006

Drine, Imed and Christophe Rault (2007) "Purchasing Power Parity for Developing and Develoed Countries: What Can We Learn From Non-Stationary Panel Data Models?", IZA Discussion Papers \#2887, Institute for the Study of Labor (IZA) 